\title{
Commentary: Moderate atrioventricular valve regurgitation may be too much to bear for a single ventricle
}

\author{
Gregory King, BBioMed, MD, and Yves d'Udekem, MD, PhD, FRACS
}

\footnotetext{
From the Department of Cardiac Surgery, Royal Children's Hospital, Melbourne, Australia; Heart Research, Murdoch Children's Research Institute, Melbourne, Australia; and the Department of Paediatrics, University of Melbourne, Melbourne, Australia.

Disclosures: Dr d'Udekem has been a consultant for Merck Sharp and Dohme and for Actelion. Dr King has nothing to disclose with regard to commercial support.

Received for publication Aug 26, 2019; revisions received Aug 26, 2019; accepted for publication Aug 26, 2019. Address for reprints: Yves d'Udekem, MD, PhD, FRACS, Cardiac Surgery Unit, Royal Children's Hospital, Flemington Rd, Parkville, VIC 3052, Australia (E-mail: yves.dudekem@ rch.org.au). J Thorac Cardiovasc Surg 2019;158:1649-51

$0022-5223 / \$ 36.00$

Copyright $(2019$ by The American Association for Thoracic Surgery

https://doi.org/10.1016/j.jtcvs.2019.08.063
}

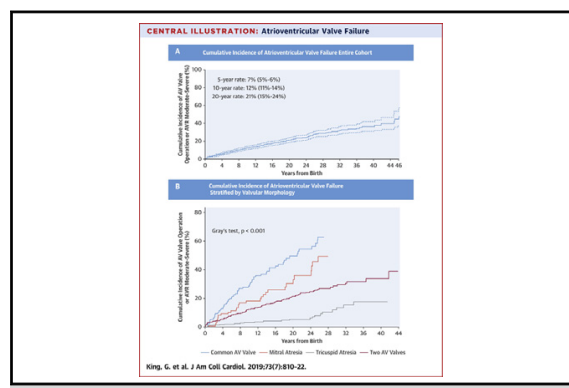

Cumulative incidence estimates for atrioventricular valve failure in Fontan survivors.

\section{Central Message}

Moderate AV valve regurgitation increases the risk of circulatory failure in the single ventricle patient. It may be time to pursue an earlier and more radical approach to valve intervention.

See Article page 1643. the common atrioventricular valves and tricuspid valves were regurgitant or necessitated intervention before patients reached the age of 25 years (Figure 1). ${ }^{2}$ The existence of even moderate regurgitation was enough to more than double a patient's risk of circulatory failure, which for most meant death or transplantation. ${ }^{2}$ Some of the opinions expressed in the review by Stephens and Dearani ${ }^{1}$ are bold and controversial, but they should be taken seriously, because these surgeons are among the most experienced of our time, especially with valve repair in congenital heart disease.

First, they strongly affirm that regurgitation should be addressed early and in a separate operation before the Fontan completion. The only exception is for a patient with a dominant left ventricle and regurgitation related to a structural abnormality of the mitral valve, in which case repair could be performed concomitantly with Fontan completion. Although most of us would follow this practice, controversy still exists regarding the patient with a systemic-pulmonary shunt and regurgitation at the time of the bidirectional Glenn shunt placement. $^{3}$ In keeping with Stephens and Dearani, ${ }^{1}$ we agree that unloading of the heart at this time is insufficient to prevent the evolution of regurgitation in these patients.

Second, Stephens and Dearani ${ }^{1}$ state unequivocally that moderate regurgitation, or even mild to moderate regurgitation, should constitute an indication for surgery. This is a departure from common practice in many parts of the world, especially in the case when regurgitation first appears after Fontan completion. In our region, of 1531 patients after Fontan completion, 157 had moderate or greater regurgitation develop, but only 17 to date have undergone reoperation. There is an enormous reluctance from cardiologists and quite possibly their patients to submit them to reoperation. In the Mayo Clinic experience, there was a $13 \%$ early mortality for valve repair after Fontan completion. ${ }^{4}$ In currently unpublished data from our region, we observed 1 early mortality after 28 valve intervention (18 repairs, 10 replacements) performed after Fontan completion. Results of valve repair have been poor because we do not yet understand the exact mechanism of regurgitation in these patients. We share the belief of Stephens and Dearani ${ }^{1}$ that we have probably overlooked the possibility of working on the subvalvular apparatus of these valves, particularly given the propensity of these single ventricles to adopt globular shapes.

Finally, Stephens and Dearani ${ }^{1}$ advocate valve replacement at a much earlier stage than it is usually used. We have all been reluctant to replace valves in congenital heart disease, but this may be a setting in which replacement is advantageous relative to a poor repair. Stephens and Dearani ${ }^{1}$ advocate swift replacement in the setting of early repair failure. In yet unpublished data, we have found an enormous mortality for patients with early repair failure, adding further weight to this argument.

Perhaps it is already time for us to intervene early and radically in these patients.

Time for a change. 


\section{CENTRAL ILLUSTRATION: Atrioventricular Valve Failure}

\section{A Cumulative Incidence of Atrioventricular Valve Failure Entire Cohort}

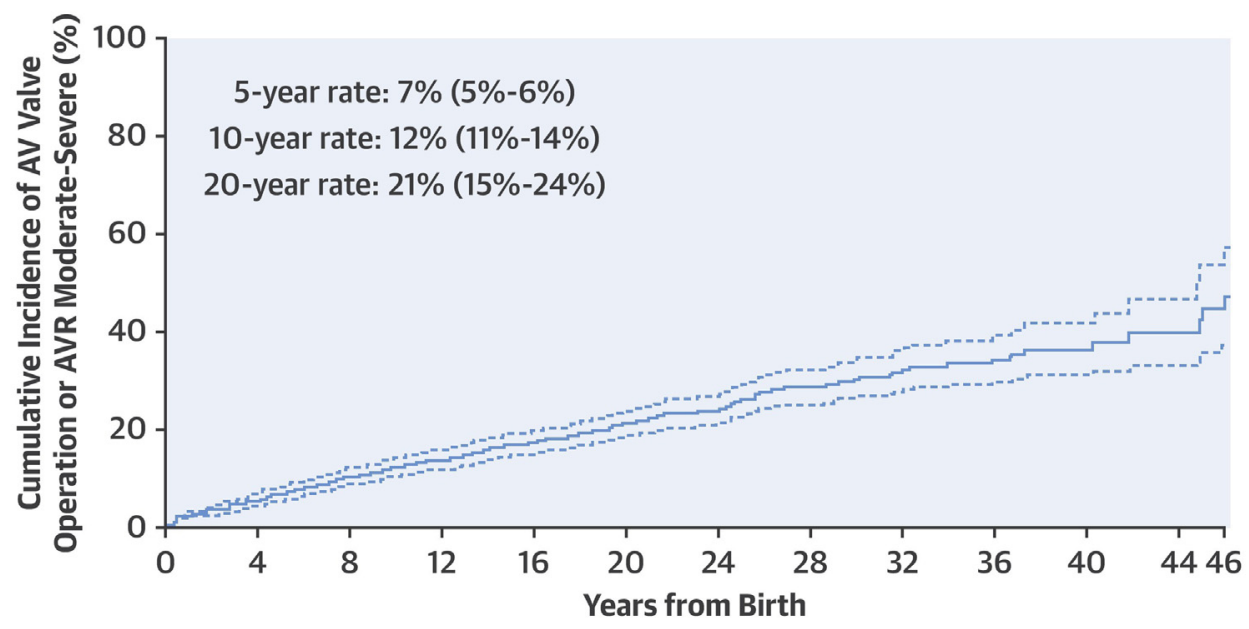

\section{B Cumulative Incidence of Atrioventricular Valve Failure Stratified by Valvular Morphology}

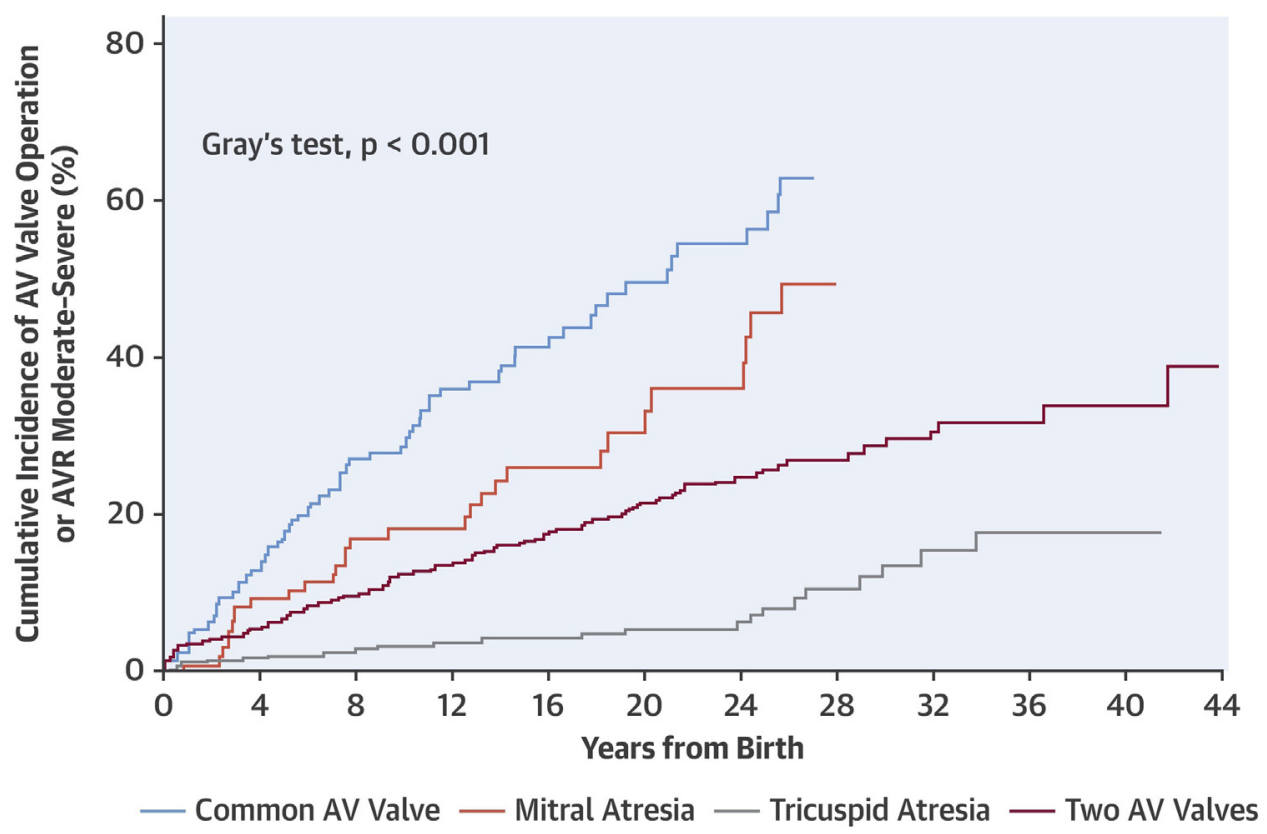

\section{King, G. et al. J Am Coll Cardiol. 2019;73(7):810-22.}

FIGURE 1. A, Cumulative incidence curve for estimated incidence of atrioventricular $(A V)$ valve failure (moderate or greater regurgitation, or valve intervention) in patients who underwent Fontan palliation and (B) cumulative incidence curve for estimated incidence of AV valve failure (moderate or greater regurgitation, or valve intervention) stratified by valvular morphology for patients who underwent Fontan palliation. Dashed lines denote $95 \%$ confidence intervals. AVR, Atrioventricular regurgitation. Reprinted from: King G, Ayer J, Celermajer D, Zentner D, Justo R, Disney P, et al. Atrioventricular valve failure in Fontan palliation. J Am Coll Cardiol. 2019;73:810-22. Copyright 2019, reprinted with permission from Elsevier. 


\section{References}

1. Stephens E, Dearani J. Management of the bad atrioventricular valve in Fontan...time for a change. J Thorac Cardiovasc Surg. 2019;158:1643-8.

2. King G, Ayer J, Celermajer D, Zentner D, Justo R, Disney P, et al. Atrioventricular valve failure in Fontan palliation. J Am Coll Cardiol. 2019;73:810-22.

3. Mahle WT, Cohen MS, Spray TL, Rychik J. Atrioventricular valve regurgitation in patients with single ventricle: impact of the bidirectional cavopulmonary anastomosis. Ann Thorac Surg. 2001;72:831-5.

4. Menon SC, Dearani JA, Cetta F. Long-term outcome after atrioventricular valve surgery following modified Fontan operation. Cardiol Young. 2011;21:83-8. 